\title{
Rationale of Aceclofenac in Management of Pyrexia in Paediatric Practice
}

\author{
Avinash Shankar*1, Amresh Shankar ${ }^{2}$ and Anuradha Shankar ${ }^{3}$ \\ ${ }^{1}$ Postgraduate in Endocrinology \& Metabolism (AIIMS Delhi), Chairman National Institute of Health \& Research Warisaliganj (Nawada), India
}

${ }^{2}$ Aarogyam Punarjeevan Ram Bhawan, India

${ }^{3}$ Centre for Indigenous Medicine \& Research Senior Research Fellow Regional Institute of Ayurveda, India

Received: 制: November 19, 2018; Published: 岿: November 28, 2018

*Corresponding author: Avinash Shankar, Postgraduate in Endocrinology \& Metabolism (AIIMS Delhi) Chairman National Institute of Health \& Research Warisaliganj (Nawada) Bihar, India

\section{Abstract}

Pyrexia, a complex physiological response triggered by infection or aseptic stimuli causes increase in Prostaglandin E2(PGE2)concentration in brain and later firing rate of neurones of thermoregulatory centre i.e. Hypothalamus. Majority attendance at paediatrician chamber are of children with pyrexia of varied origin and to calm the temperature at optimal level various therapeutics are in vogue but attendance of children with antipyretics adversity presenting as morbidity and mortality necessiated an evaluation of presenting hazards with consuming antipyretics.

Objective of Study: Analyse the rationality of Aceclofenac paracetamol combination, as antipyretics in paediatric practice.

Material \& Methods: Analysis of datasheet of patients admitted with antipyretics adversity at Centre For Children Disease \& Research.

Result: Children consuming Aceclofenac Sodium Paracetamol presented with grave status of prolonged hypothermia, CNS disturbances like Dizziness, Convulsion, coma in addition to more pronounced other presentation like persistant vomiting, haematemesis, blood dyscariasis, rash, albuminuria than other.

Conclusion: Acceclofenac sodium Paracetamol combination must be restricted for paediatrics use considering its dreaded outcome.

Keywords: Pyrexia; Prostaglandin; Hypothalamus; Thermoregulatory; Cns Disturbances Hypothermia; Blood Dyscariasis; Albuminuria

\section{Introduction}

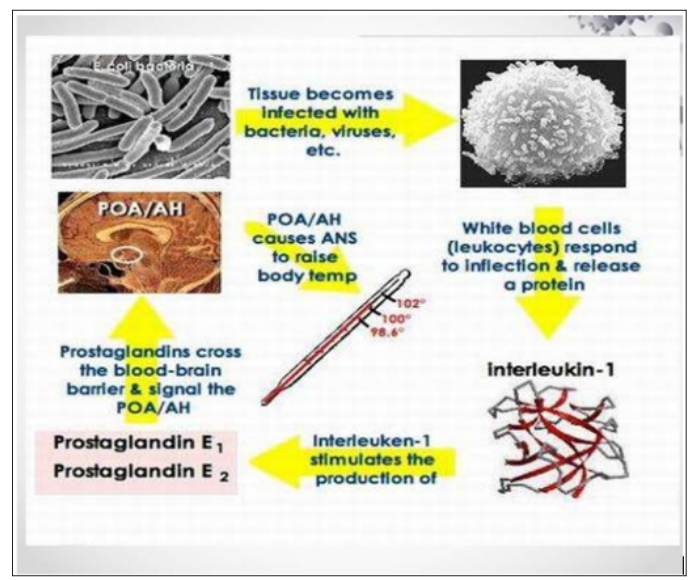

Figure 1: Schematic presentation of Fever generation.
Pyrexia, a common clinical presentation of varied clinical conditions estimating $1 / 3$ of all children visit to health care centre and parent usually self-medicate their children with the over the counter (OTC) antipyretics [1]. Fever is a beneficial outcome of the physiologic response triggered by infection or aseptic stimuli as it boost immunity against the invading pathogen, though beyond certain level it may cause discomfort and organic damage which usually presents with febrile convulsion [2,3] (Figure 1). Fever up to $1020 \mathrm{~F}$ is considered beneficial but $>1020 \mathrm{~F}$ become harmful and disastrous thus medication needed to keep the temperature $<1020 \mathrm{~F}[4,5]$. Fever result from an immune response mediated through the action of cytokinin on thermoregulatory centre of the brain or by conserving heat through vaso- constriction manifesting as Chills Or generating heat by active muscular contraction i.e.rigor (Figure 2). During fever in addition to specific therapeutics the molecules usually prescribed is antipyretics and the commonly 
prescribed are - Paracetamol (Acetaminophen); Mefenamic acid Ibuprofen and Nimesulide either alone or in combination with paracetamol, but these days Aceclofenac and paracetamol being commonly prescribed and sold as over the counter antipyretics in children [6-9].

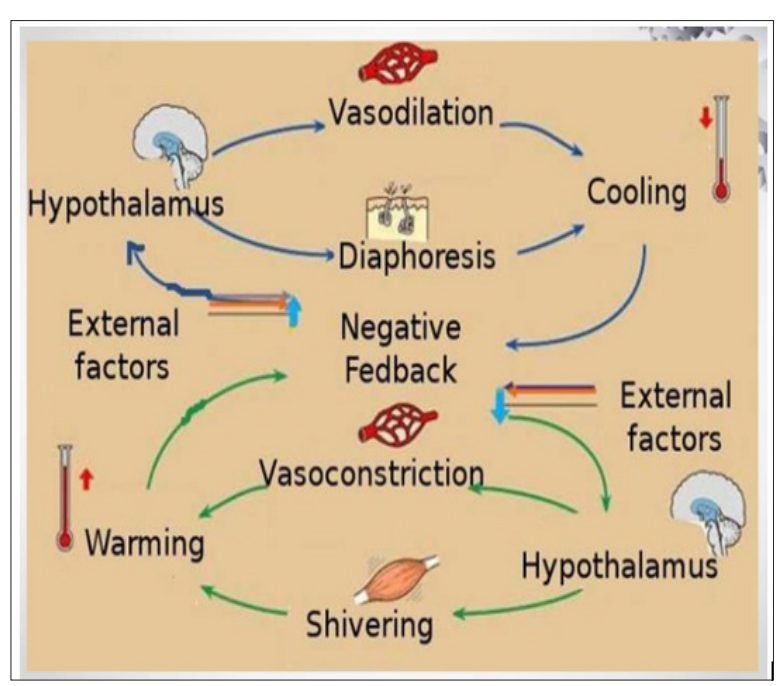

Figure 2: Schematic representation of Thermal haemostasis.

Fever may be suppressed by antipyretic or by physical cooling During antipyretics prescription safety profile must be choice as majority of antipyretic are equally effective and their proper dose and administer schedule must be ensured $[10,11]$. Most antipyretics act by inhibiting the enzyme Cyclo oxygease and reduces PGE2 within the hypothalamus but may be due to reduction of pro inflammatory mediator, increased anti inflammatory signals or boost antipyretic message within the brain $[12,13]$. Usually village practitioner follow the prescription of qualified clinician and over the counter drugs are being used only when manufacturer come with these products with due permission from FDA. Availability of Aceclofenac sodium -paracetamol suspension being rampantly used for pyrexia in children. As drug formulation approval is the responsibility of FDA, this study is being conducted with an intent to assess the rationality of Suspension Aceclofenac with paracetamol as an antipyretic for children.

\section{Objective of the Study}

Analysis of untoward effects observed in children taking Aceclofenac-Paracetamol combination for treatment of fever.

\section{Duration of Study}

Patients attended the centre between January 2016- February 2018.

\section{Material \& Methods}

\section{Material}

Children suffering with pyrexia and consumed Aceclofenac sodium -paracetamol combination and admitted at Centre For Research in Children Disease, RA. Hospital \& Research Centre, Warisaliganj (Nawada) Bihar with unusual presentation been selected for analysis.

\section{Method}

Patient's parent or attendant were interrogated for therapeutics taken, its dose administration and appearance of the manifestation, clinically examined and investigated for haematological, hepatic and renal profile. Patients presenting with hypothermia, perspiration, hypotension, cardiac dysrhythmia unconsciousness and convulsion were treated accordingly.

\section{Observations}

Children consuming various antipyretics for relief of fever and attending at Centre for Children Disease Research were of age group <1->5 years majority $614(22.7 \%)$ patients of age group 4-5 years (Table 1). Out of all 1700 were male and 1000 female (Figure 3) Out of all 25\% were taking Aceclofenac -paracetamol while $4.2 \%$ only paracetamol though $34 \%$ patients were taking Nimesulide \& paracetamol (Table 2). Though nausea remain a common manifestation among all patients of varied therapeutic group, but manifestation like Dizziness, rash, GI bleeding, blood dyscariasis, convulsion, prolonged hypothermia remain more pronounced with marked albuminuria in patients taking Aceclofenac sodium Paracetamol combination. Patients taking Aceclofenac paracetamol presenting with adversity like Dizziness, convulsion and sustained hypothermia resulted in an eventful fate i.e. mortality in 20 cases out of 674 but none of other group (Table 3). Onset of antipyretic effect was similar in all the groups sustained prolonged hypothermia was very common in patients consuming Aceclofenac sodium Paracetamol than Nimesulide -paracetamol (Figure 4).

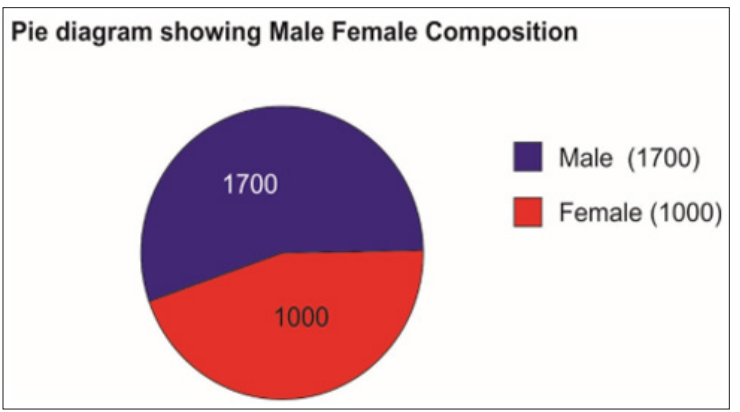

Figure 3: Pie diagram showing Male female Composition.

Table 1: Age \& sex wise distribution of patients.

\begin{tabular}{|c|c|c|c|c|}
\hline \multirow{2}{*}{ Age Group (In Years) } & \multicolumn{4}{|c|}{ Number of Patients } \\
\cline { 2 - 5 } & Male & Female & Total & $\%$ \\
\hline$<1$ & 138 & 94 & 232 & 8.6 \\
\hline $2-3$ & 238 & 142 & 380 & \\
\hline $3-4$ & 312 & 212 & 524 & \\
\hline $4-5$ & 308 & 202 & 510 & \\
\hline$>5$ & 406 & 208 & 614 & \\
\hline & 298 & 146 & 444 & \\
\hline
\end{tabular}


Table 2: Distribution of patients as per their therapeutics.

\begin{tabular}{|c|c|c|}
\hline Therapeutic group & Number of patients & $\mathbf{\%}$ \\
\hline Acceclofenac sodium + Paracetamol & 674 & 25 \\
\hline Nimesulide +Paracetamol & 924 & 34 \\
\hline Ibuprofen +Paracetamol & 474 & 17.5 \\
\hline Mefinamic acid +Paracetamol & 322 & 12.0 \\
\hline Nimesulide & 208 & 7.3 \\
\hline Paracetamol & 98 & 4.2 \\
\hline
\end{tabular}

Table 3: presentation observed during therapy.

\begin{tabular}{|c|c|c|c|c|c|c|}
\hline \multirow{2}{*}{ Presentations } & \multicolumn{6}{|c|}{ Number of cases in various group of therapy } \\
\hline & AP & NP & IP & MP & N & P \\
\hline & $\mathbf{6 7 4 )}$ & $\mathbf{( 9 2 5 )}$ & $\mathbf{( 4 7 4 )}$ & $\mathbf{( 3 2 2 )}$ & $\mathbf{( 2 0 8 )}$ & $\mathbf{( 9 8 )}$ \\
\hline Nausea & 425 & 306 & 138 & 102 & 50 & 06 \\
\hline Vomiting & 288 & 103 & 60 & 32 & - & - \\
\hline Dyspepsia & 300 & 108 & 68 & 40 & - & - \\
\hline Abdominal colic & 342 & 110 & 92 & 46 & - & - \\
\hline Dizziness & 208 & - & - & - & - & - \\
\hline Rash & 196 & - & - & - & - & - \\
\hline GI bleeding & 12 & - & - & - & - & - \\
\hline $\begin{array}{c}\text { Blood } \\
\text { dyscariasis }\end{array}$ & 37 & - & - & - & - & - \\
\hline $\begin{array}{c}\text { Convulsion } \\
\text { Prolonged } \\
\text { hypothermia }\end{array}$ & 78 & - & - & - & - & - \\
\hline
\end{tabular}

Note: Key : AP :Aceclofenac Sodium -Paracetamol; NP: Nimesulide -Paracetamol; IP: Ibuprofen -Paracetamol; MP: Mefenamic acid-paracetamol; N: Nimesulide; P: Paracetamol.

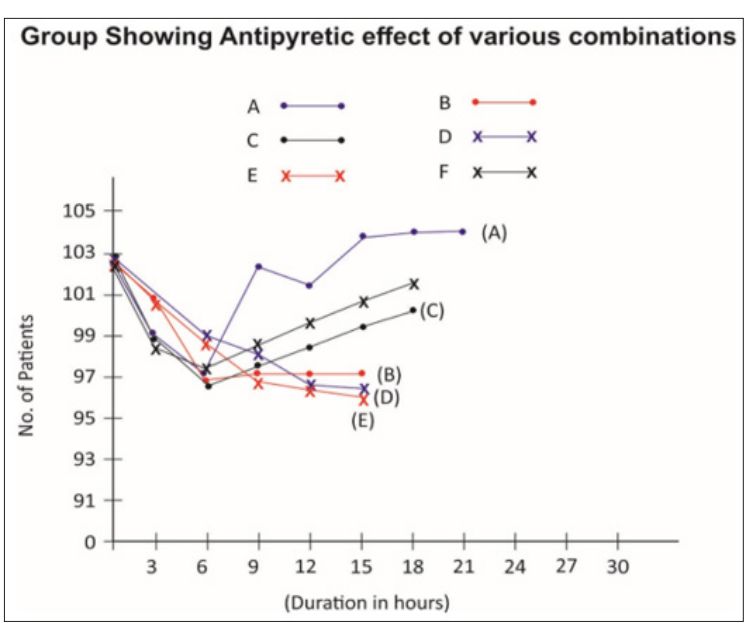

Figure 4: Group Showing Antipyretic effect of various combinations.

\section{Result}

Antipyretic available shows equi anti pyretic effect for varied duration. Patients taking Acceclofenac- Paracetamol combination shows highest drug adversity in children than other anti-pyretic s, with dreaded toxicity like prolonged and sustained hypothermia resulting in morbidity and mortality, thus must be restricted its use as antipyretics.

\section{Discussion}

Pyrexia remain a major cause of children attendance at Clinician chamber and majority comes with use of various over the counter antipyretics or treated by local practitioners. As to calm the fever use of antipyretic is an Ernest need but must be used with due caution as -Evaluation of data sheet of children presenting with fever of varied origin taking various antipyretic and presenting with sequel suggest pronounced drug adversity with Acceclofenac sodium -paracetamol combination than other i.e.- dizziness, rash, blood dyskaryosis, marked albuminuria, convulsion, sustained and prolonged hypothermia resulting in brain death. Most antipyretics act by inhibiting the enzyme Cyclo oxygenase and reducing the level of PGE2 within the hypothalamus but may be due to reduction of pro inflammatory mediators, increase anti-inflammatory signals or boost anti pyretic messages within the brain (Figure 5).

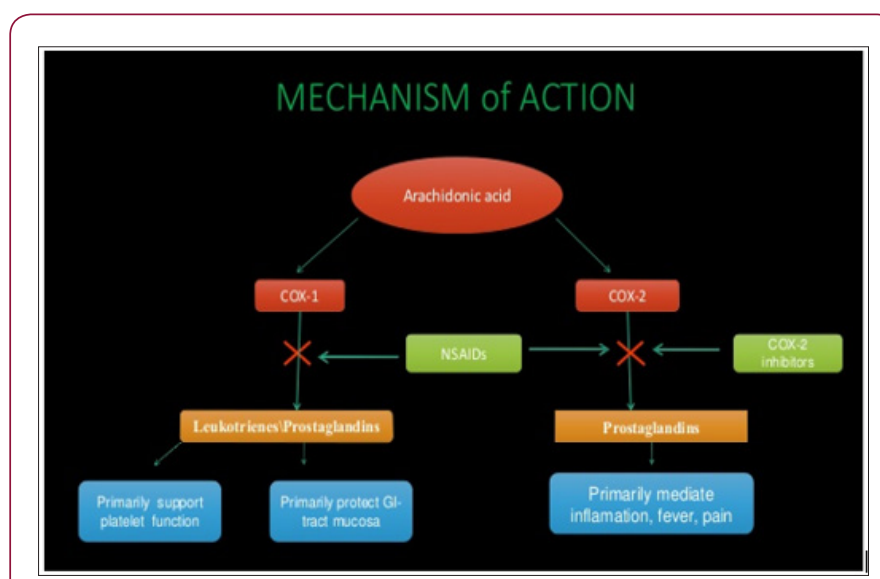

Figure 5: Schematic presentation of Antipyretic action.

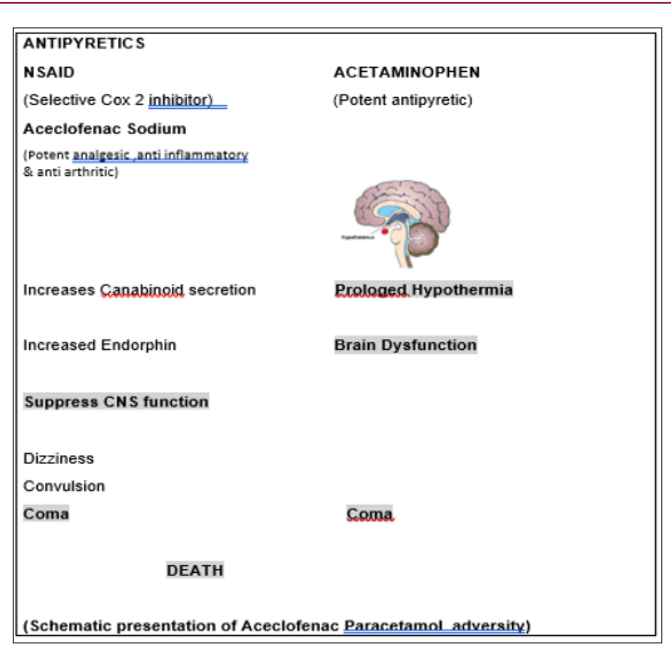

Figure 6: Schematic presentation of Aceclofenac paracetamol adversity.

Aceclofenac sodium is an orally effective non-steroidal anti-inflammatory drug of phenyl acetic acid group possessing remarkable anti-inflammatory, analgesic and antipyretic properties but usually a choice prescription for rheumatoid arthritis, osteoarthritis and ankylosing spondylitis, but not recommended in children. Aceclofenac shows more selective effect towards COX2 than COX 1 and inhibits synthesis of Prostaglandin (PGE2), a product 
of inflammatory cytokine, interleukin and tumour necrosis factor, in addition also affect cell adhesion molecules from neutrophil $[14,15]$. This also interrupts the endo cannabinoid system and endocannabinoid [16,17] as COX2 utilizes endo cannabinoid as a substrate and plays key role in producing drug adversity specially in children, pregnant and breast-feeding mother (Figure 6).

\section{Conclusion}

Considering the untoward effects causing morbidity and mortality with Aceclofenac Sodium -Paracetamol, its advocation in children must be restricted.

\section{References}

1. May A, Bauchner H (1992) Fever phobic the paediatrician's contribution. Paediatrics 90: 851-854.

2. El-Radhi AS, Carroll J (1994) Fever in paediatric practice. Oxford: Blackwell Scientific Publications pp. 243.

3. Solomon HC, Kopp I (1937) Fever therapy. N Engl J Med 217: 805-814.

4. Pearce C, Curtis N (2005) Fever in children. Aust Fam Pract 34: 769771.

5. Gurer US, Palanduz A, Gurbuz B, Yildirmak Y, Cevikbas A, et al. (2002) Effect of antipyretics on polymorphonuclear leukocyte functions in children. Int Immunopharmacol 2(11): 1599-1602.

6. Walsh A, Edwards H, Fraser J (2007) Over-the-counter medication use for childhood fever: a cross-sectional study of Australian parents. J Paediatr Child Health 43(9): 601-606.

7. Goldman RD, Ko K, Linett LJ, Scolnik D (2004) Antipyretic efficacy and safety of ibuprofen and acetaminophen in children. Ann Pharmacother 38(1): 146-150.

ISSN: 2574-1241

DOI: 10.26717/BJSTR.2018.11.002112

Avinash Shankar. Biomed J Sci \& Tech Res

(C) (i) This work is licensed under Creative

Submission Link: https://biomedres.us/submit-manuscript.php
8. Li SF, Lacher B, Crain EF (2000) Acetaminophen and ibuprofen dosing by parents. Pediatr Emerg Care 16(6): 394-397.

9. Wright AD, Liebelt EL (2007) Alternating antipyretics for fever reduction in children: an unfounded practice passed down to parents from pediatricians. Clin Pediatr (Phila) 46(2): 146-150.

10. Mayoral CE, Marino RV, Rosenfeld W, Greensher J (2000) Alternating antipyretics: is this an alternative? Pediatrics 105(5): 1009-1012.

11. Goldman RD, K0 K, Linett LJ, Scolnik D (2004) Antipyretic efficacy and safety of ibuprofen and aceta minophen in children. Ann Pharmacother 38(1): 146-150.

12. Wright AD, Liebelt EL (2007) Alternating antipyretics for fever reduction in children: an unfounded practice passed down to parents from pediatricians. Clin Pediatr 46(2): 146-150.

13. Ngong JM, Waring RH (1994) Circadian rhythms of paracetamol metabolism in healthy subjects: A preliminary report. Chronobiology Drug Metabol Drug Interact 11(4): 317-330.

14. Shankar A (1999) comparative evaluation of antipyretic effect of Nimesulide versus Ibuprofen, Mefenamic acid and Paracetamol in pediatric practice. The Antiseptic 96(12): 457-459.

15. Mc Carthy PL (Ed) (1999) Fevers and the Evaluation of the Child with who has Fever. Philadelphia: Saunders pp. 157-163.

16. Grau M, Guasch J, Montero JL, Felipe A, Carrasco E, et al. (1991) Pharmacology of the potent new non-steroidal anti-inflammatory agent aceclofenac. Arzneimittel Forschung 41(12): 1265-1276.

17. Grau M, Montero JL, Guasch J, Felipe A, Carrasco E, et al. (1991) The pharmacological profile of aceclofenac, a new nonsteroidal antiinflammatory and analgesic drug. Agents Actions 32: 125-129.

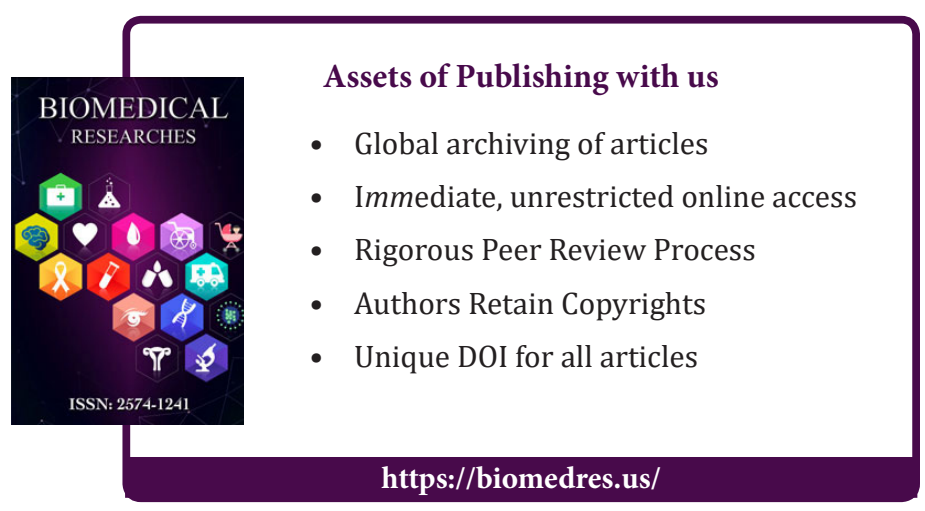

